\title{
A renewable resource model of health decision-making: insights to improve health marketing
}

\author{
Sarah Lord Ferguson $^{1}$ [D $\cdot$ Pierre Berthon ${ }^{2}$
}

Received: 10 January 2020 / Accepted: 3 October 2021 / Published online: 28 October 2021

(c) Academy of Marketing Science 2021

\begin{abstract}
A primary goal of health marketing is to help people make healthy choices. The problem is that health decision-making is complex, and individuals often make unhealthy decisions even when healthy options are promoted. In this paper, we address this problem by integrating literature in marketing, psychology, economics, medicine, and health to develop a new conceptual model: Health as a Renewable Resource, that can be readily used by marketers to help people manage their health-impacting decision. It is apparent that people view health as, in part, renewable and fungible. Underpinning this, we argue that people have an implicit model of health, analogous to a reservoir. This reservoir can be filled or drained, such that trade-offs in health-impacting decisions can be made over time. The reservoir's inputs and outputs are controlled by behavioral choices and unconscious processes including biological and environmental mechanisms. The practical and research applications of the model are outlined.
\end{abstract}

Keywords Health marketing · Consumer decision-making · Consumer well-being · Consumer psychology

\section{Introduction}

The role of individual decisions on health outcomes has been brought into sharp relief during the COVID pandemic. Consequences of choices made by the individual have been shown to extend far beyond the decision-maker, to impact families, communities, and entire societies. Moreover, these impacts manifest in multiple domains, from direct health, to education, economics, and politics (e.g., Bonaccorsi et al., 2020).

The growing field of health marketing (Bernhardt, 2006; Crié \& Chebat, 2013; Stremersch, 2008) is predicated upon the desire to help people make healthy behavioral choices. The problem is that many individuals often make unhealthy decisions even when healthy options are available. Moreover, there appears to be no simple answer to this problem. Health is a complex construct and what behaviors are perceived to be healthy, and in what amounts, varies between individuals (e.g., Raghunathan et al., 2006). Furthermore,

Sarah Lord Ferguson

st110@sfu.ca

1 Beedie School of Business, Simon Fraser University, Vancouver, Canada

2 McCallum Graduate School of Business, Bentley University, Waltham, USA engaging in healthy behaviors does not guarantee perfect health, and indulging in unhealthy behaviors always manifests in illness. Yet, chronic diseases such as diabetes, heart disease and obesity, which are strongly linked to modifiable behavioral risk factors (e.g., poor diet, sedentary lifestyle), continue to account for the vast majority of health care spending and comprise about 70 percent of deaths worldwide (World Health Organization, 2018).

Experts agree that engaging in behaviors such as exercising regularly, eating vegetables, getting adequate sleep, and quitting smoking greatly reduces one's risk of developing various physical and mental diseases (Schmidt, 2016; Willett et al., 2006). However, marketing the health benefits associated with these behaviors, alone or in conjunction with, the risks of unhealthy behaviors does not always result in individuals making healthier choices. Therefore, a multifaceted understanding as to the when, where, why, and how individuals engage in health-impacting behaviors is key to designing and executing marketing initiatives that have a greater influence on individuals' health decision-making processes.

As such, research plays an important role in informing health marketing interventions and policy changes to fight chronic diseases and improve the well-being of our societies. However, the broad and disjointed nature of health 
decision-making research to date presents challenges for health marketers looking to derive practical applications from scholarly work. At the macro-level, researchers in population and public health have proposed the Social Determinants of Health as a set of non-medical factors (e.g., one's social and physical environment) that influence the choices available to individuals and their associated health outcomes (Marmot \& Wilkinson, 2006). Many of these factors are outside of the individuals' immediate control and require solutions at the global, country, regional and community level (Marmot et al., 2008). In contrast, researchers in psychology, behavioral economics, marketing and consumer behavior have revealed micro-level explanations for health decision-making that can be more readily used by health marketers to nudge individuals towards healthy behaviors (Malkoc \& Zauberman, 2019; Thaler \& Sunstein, 2009).

Still, the practical application of this research is limited in various ways making the leap from research to health marketing intervention complicated. For instance, much of our understanding of the individual-level factors influencing decision-making is based on laboratory studies, which provide an ideal setting for isolating and manipulating variables, but invariably fails to fully replicate the circumstances under which real-world decision-making occurs (Pham, 2013). Moreover, even among individual-level decision-making research, no unifying theory or framework of decisionmaking is recognized (Berns et al., 2007).

Considering this, work aimed at developing frameworks and conceptual models of health decision-making that integrate not only cognitive, psychological, and affective factors, but also the social determinants of health is sorely needed. The purpose of our paper is to contribute to this goal by introducing a new conceptualization of health and a corresponding model of health decision-making that has several practical and theoretical applications. First, the model was created by reviewing and integrating literatures in marketing, psychology, economics, medicine, and health, thus making an interdisciplinary contribution to our understanding of decision-making around health. Second, the model can be easily understood by the layperson and utilized by health marketers to positively influence health behaviors. Third, the model provides a foundational case for a novel stream of research that explores the impact that implicit and explicit metaphors have on people's health decisions.

The paper proceeds as follows. First, we review existing literature about how individuals tend to make health decisions. Second, integrating and building on this literature, we develop a new conceptual model: Health as a Renewable Resource. In doing so, we argue that people have an inferential model of health, homologous to a reservoir. This 'health' reservoir can be filled or drained, such that tradeoffs in health resources can be made over time. The reservoir's inputs and outputs are regulated by both conscious (voluntary) behavioral choices and unconscious (nonvoluntary) processes including biological and environmental mechanisms. We conclude with a discussion of the practical applications of the model and the research opportunities that it affords.

\section{Health decision-making and intertemporal choices}

Aside from macro-socioeconomic factors, individual health decision-making often involves trade-offs or conflicts between what is immediately satisfying and what is best for one's long-term health (Urminsky \& Zauberman, 2017). For instance, the decision to smoke cigarettes today may satisfy a craving or provide a calming effect on the body, but it is also well-known that habitual smoking increases an individual's risk of developing lung cancer (Gandini et al., 2008). Akin to this example are many health behaviors that provide short-lived benefits, but when repeated regularly increase the risk of developing debilitating, chronic and potentially lifethreatening conditions such as diabetes, cancer, and heart disease (World Health Organization, 2018).

As a result, health decisions can be classified as intertemporal choices, which involve weighing costs and benefits over time when one's decisions result in delayed future consequences or rewards (Malkoc \& Zauberman, 2019). Intertemporal choices are often commonly studied by comparing discount rates, defined as the rate at which individuals trade off present for future gains or losses (Read, 2004). In general, the higher the discount rate, the faster future outcomes are devalued, which results in biases towards choices that give present utility.

Many researchers have demonstrated that individuals tend to suffer from temporal myopia or short-sightedness when considering intertemporal choices (e.g., Thaler, 1981). Instead of exhibiting a time-consistent discounting pattern, individuals often make decisions consistent with hyperbolic discounting or the tendency "to increasingly choose a smaller-sooner reward over a larger-later reward as the delay occurs sooner rather than later in time" (Redden, 2007, p.1). Put simply, most people are willing to endure future consequences, including forgoing future gains, in order to benefit from a reward, the sooner it occurs to the present moment. This pattern has been observed in decision-making about finances (e.g., Loewenstein \& Prelec, 1992), environmental impact (e.g., Hardisty \& Weber, 2009) and health outcomes (e.g., Chapman, 1996). 


\section{Explanations for short-sighted ${ }^{1}$ health decision-making}

Researchers in psychology, economics, and the consumer behavior subdiscipline of marketing have sought to understand what accounts for the disconnect between the present self who enjoys the utility associated with unhealthy decisions and the future self who incurs a greater risk of developing and living with the negative health consequences of their choices. Given the complex and multifaceted nature of health and intertemporal choices, it is not surprising that multiple explanations have been proposed (Urminsky \& Zauberman, 2016). We conducted a thorough literature review to explore the commonalities and differences in these explanations, which informed the development of our conceptual model. Our findings are described below and summarized in Table 1.

\section{Affective drivers}

Early work seeking to explain health decision-making focused on the influence of affective drivers or visceral factors such as emotions (e.g., disgust) and physiological drive states including hunger (Loewenstein, 1996). The influence of these factors has been shown to result in short-sighted preferences (Lerner et al., 2013) and a strong motivation to consume unhealthy foods (Shiv \& Fedorikhin, 1999). For example, if a person is completely famished, they may care less about the health properties of the food they are about to consume and more about simply satisfying the need to eat. Alternatively, an individual may choose their foods based on emotional cues such as consuming "comfort" foods to make themselves feel better when they are upset. This strategy represents stereotypical depictions of people "eating their feelings" and is one of the simplest explanations for the drive to satisfy bodily urges and emotional cues with unhealthy options even when healthy options are available.

\section{Trait characteristics}

While affective drivers represent transient states (i.e., hunger passes when satiated), other explanations for short-sighted health decision-making have been attributed to stable trait characteristics, often thought of as part of one's personality. For example, some individuals have been shown to

\footnotetext{
1 Although short-sighted (vs long-sighted) health decisions have been the primary focus of the research studies reviewed, we point out that they are a subset of the larger set of "balanced vs unbalanced" health choices. Balanced health decisions weigh the positive, negative, and uncertain implications of health-related behaviors over time (short-term vs long-term), amount (too little vs too much) and context (appropriate vs inappropriate). Unbalanced do the opposite.
}

demonstrate a high degree of what researchers describe as present bias-a strong preference for immediate rewards, or more simply, a quantification of patience and self-control (Read, 2004). Variation in this trait characteristic may explain why some individuals consistently make short-sighted decisions in several areas of their life, while others exhibit more restraint or self-control. In a meta-analysis examining a variety of intertemporal choices, MacKillop et al. (2011) found that people who had trouble saving money were also more likely to engage in addictive behaviors including excessive drinking, smoking and the use of stimulant and opioid drugs. Similarly, Komlos et al. (2003) demonstrated that those with a higher Body Mass Index were more likely to choose a smaller, but sooner financial reward in their studies. These findings provide support for the present bias trait explanation by showing that individuals who are short-sighted with financial decisions are also more likely to also exhibit this bias when it comes to health-impacting behaviors.

\section{Time perception}

The way in which individuals perceive the passage of time may also influence health decision-making, especially when time is experienced in a non-linear fashion (Zauberman et al., 2009). In general, people tend to perceive time to be passing quickly when experiencing pleasure (e.g., having dinner with friends), and view time as passing slowly when experiencing discomfort (e.g., getting a mammogram). In this way, some health-benefitting behaviors may elicit the perception of a prolonged time of disutility, which some individuals may have difficulty tolerating. When individuals perceive time to be passing slowly, they may be more likely to give into temptations and engage in unhealthy behaviors, or alternatively, they may avoid or stop engaging in health-benefiting behaviors prematurely (Kim \& Zauberman, 2009).

\section{Construal level theory}

Another explanation for short-sighted decision-making involves the way in which individuals visualize the future. In their theory on Construal Level, Liberman and Trope (1998) explain that while the near future may be represented concretely in the mind, the distant future may be more abstract. When it comes to health decision-making, this phenomenon may result in decisions that are biased away from the future. Specifically, the utility that an individual would gain in the short-term (e.g., the taste of a candy or the relaxing feeling from smoking) is seen as very salient compared with the intangible and abstract potential future consequences of those actions. Studies have shown that the extent to which one is able to visualize the future influences the amount of self-control that a person exhibits (Fujita et al., 2006) and the number of short-sighted decisions (Malkoc et al., 2010). 


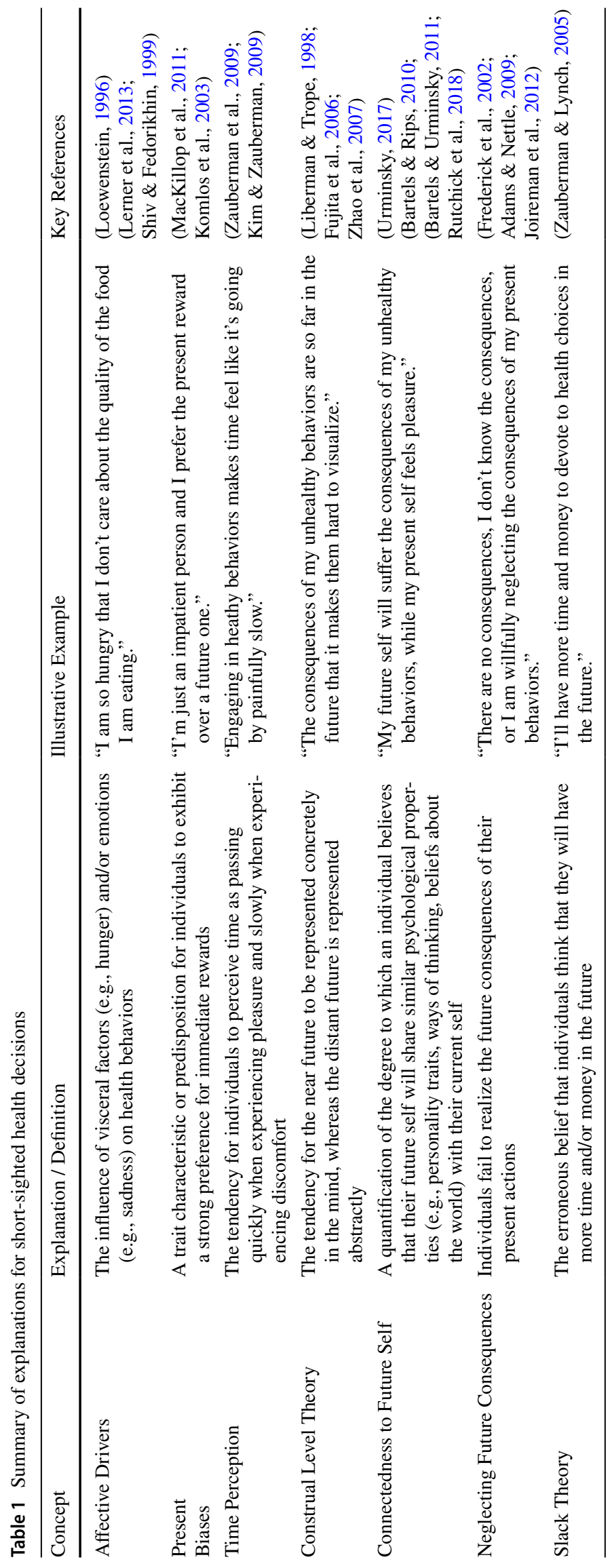




\section{Connectedness to future self}

A similar concept is connectedness to future self, defined as the degree to which an individual believes that their future self will share similar psychological properties such as personality traits, ways of thinking, and beliefs about the world, with their current self (Urminsky, 2017). Those low in connectedness to future self tend to view an older version of themselves as a completely different person, whereas those high in connectedness to future self are more likely to believe that their future self will think, feel, and act similarly to their present self (Hershfield \& Bartels, 2018). When it comes to health decisions, Urminsky (2017) explains that individuals may make unhealthy choices in the present because they do not identify with their future self. They may have difficulty imagining being the person living with the consequences of their actions today, especially when those consequences take years to manifest. However, researchers have demonstrated that asking participants to imagine and connect with their future self can have positive effects on self-control (Zhao et al., 2007) and exercise behavior (Rutchick et al., 2018). Thus, variations in connectedness to future self are associated with individual differences in how people value the future and make health decisions (Bartels \& Rips, 2010; Bartels \& Urminsky, 2011).

\section{Neglecting future consequences}

It is also possible that individuals fail to even consider the consequences of their decisions regardless of how far in the future they will be experienced. Frederick et al. (2002) suggests that this results from a lack of cognitive processing, whereby people tend to neglect opportunity costs and future consequences. Other researchers have shown that when the future consequences of individuals' decisions are made more salient, they are more likely to: practice patience with their finances (Magen et al., 2008); consume less alcohol, drugs, and cigarettes (Adams \& Nettle, 2009); exercise and eat a healthy diet (Joireman et al., 2012); undergo cancer screenings (Picone et al., 2004); and engage in safer sexual practices (Rothspan \& Read, 1996). These findings demonstrate that individuals may not always take the time to think through the future risks and consequences of their decisions unless prompted to do so. Yet, as demonstrated with Construal Theory and the concept of connectedness to future self, it is not always enough to know the consequences or risks associated with behaviors. The most positive healthimpacting decisions likely result from individuals not only being aware of the consequence of their actions, but also the specifics of what life would look like living with those consequences and a strong connectedness to the person (their future self) who would live through those consequences.

\section{Slack theory}

A final explanation for short-sighted health decisions pertains to the amount of time and money that individuals perceive they will have in the future. In their work on Slack Theory, Zauberman and Lynch (2005) use the concept of slack, defined as "the perceived surplus of a given resource available to complete a focal task" (p.23), to explain why individuals may delay engaging in various behaviors such as saving money or exercising. Over short time spans (e.g., week to week, month to month), the authors find that people expect both time and money slack to be greater in the future compared with the present. As a result, individuals may postpone healthy behaviors because they think that they will have more time and/or money available to commit to them later. However, most individuals tend to have the same amount of time and money available in the near future as they have in the present. Zauberman and Lynch (2005) describe this phenomenon as the "yes-damn effect" referring to how individuals often make commitments in advance thinking that they will have more time later, only to resent themselves for making said commitments because they are just as busy as when they made the commitment in the first place. Thus, future slack perceptions constitute a flawed rationalization strategy for unhealthy present behaviors that fails to promote healthy choices in the future.

\section{Integrating intertemporal choice and health literature}

While researchers studying intertemporal choice have identified the many factors that influence health decision-making (Table 1), a unifying theory of intertemporal choice and health has yet to be proposed (Berns et al., 2007). Nonetheless, in reviewing the literature above, some important observations can be made that have promise for integrating the various explanations for short-sighted health decisionmaking. For instance, one commonalty in intertemporal choice research lies in the fact that unhealthy decisions resulted from mechanisms that alter individuals' attitudes towards and perceptions of time. With this understanding, the explanations for short-sighed decision-making can be distilled down into three distinct influences: 1) bias towards the present, 2) bias away from the future, ${ }^{2}$ and 3 ) temporal asymmetry.

\footnotetext{
${ }^{2}$ It is important to note that past and future are not antithetical. Bias towards the present is the active focus on short-term effects (positive, negative, or uncertain), whereas bias away from the future is the active discounting or ignoring of long-term effects (positive negative, or uncertain). Technically there are four categories to consider: bias towards the present, bias away from future, bias towards the future and bias away from the present. Thus, short- and long-term focus are best considered as orthogonal dimensions.
} 
Take, for instance, affective drivers (e.g., hunger, emotions, and urges) and other present moment discomforts, which act by biasing individuals towards decisions that favor utility in the present moment. On the contrary, willful ignorance, connectedness to future self and Construal Theory act by biasing decisions away from the distant and unclear future. The remaining explanations, including altered time perception and Slack Theory result in temporal asymmetry such as when individuals rationalize decisions with the erroneous belief that things will be different in the future.

While these factors may act in isolation, it is more likely that a combination of bias toward the present, bias away from the future and temporal asymmetry influence decision-making in the real-world context, which also includes macro-level factors. For instance, consider a scenario in which a present biased individual (i.e., decreased trait patience and selfcontrol) experiences a present moment discomfort or dislike, which then gives them the perception that time is passing agonizingly slow. Here not only does the individual experience temporal asymmetry (driven by an altered perception of time passing), but also strong biases toward the present moment that are driven by the desire to avoid current discomforts and the individual's innate trait characteristics. If that same person also has difficulty visualizing the future, neglects the future consequences of their actions and/or feels disconnected from their future self, decision-making is further impacted by biases away from the future. In this way, the factors that impact health decision-making may act through various levels of cognition, some considered consciously as a rationalization strategy (e.g., I'll exercise tomorrow when I have more time), and others acting on an unconscious level (e.g., personality traits). Moreover, other factors, some conscious (e.g., income) and some unconscious (e.g., genetics), are known to influence health-impacting decisions and their outcomes.

Figure 1 provides a visual representation integrating the various explanations for short-sighted health decision-making including the psychological factors reviewed above as well as macro-level factors (e.g., environmental factors and the social determinants of health) as shown in the outer circles (Khullar \& Chokshi, 2018). Moving inwards toward the center of the figure are the individual level factors that can be simplified into the three influences (bias toward the present, bias away from the present, and temporal asymmetry). These influences result in short-sighted decision-making unless circumstances are altered to produce more future focused thinking patterns. Such was the case in the aforementioned studies that positively manipulated psychological factors including construal levels and connectedness to future self, which resulted in choices that tended to favor individuals' future health and well-being. But, as Fig. 1 demonstrates, simply altering one of these factors alone may not be enough to result in sustained positive changes in health decision-making in real-world settings over time.

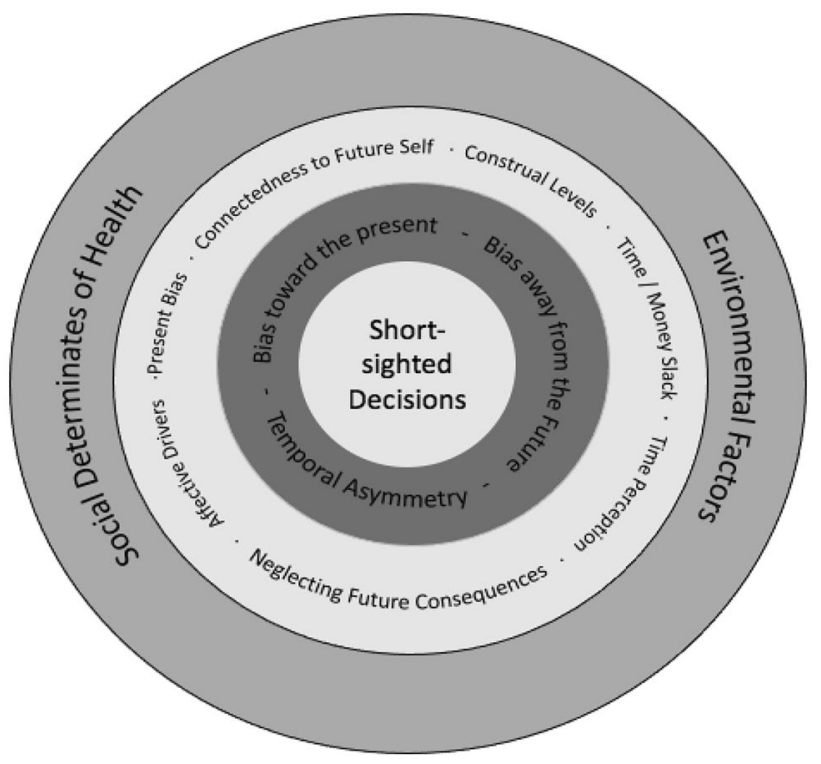

Fig. 1 Factors influencing health decision-making

\section{Intertemporal health research limitations and motivation for new conceptual model}

While intertemporal choice studies to date have improved our understanding of the various explanations driving shortsighted decision-making, they are somewhat limited in their practical applications for at least three reasons. First, most intertemporal choice research to date has focused heavily on the results of laboratory experiments that have examined one of the many individual-level factors that influence decision-making in isolation. While this approach is useful for identifying and manipulating constructs to gain a greater understanding of their influences, it may be difficult to apply these manipulation techniques outside of the laboratory, thus limiting the practical implications of the studies (Pham, 2013). Second, the field of intertemporal choice is relatively new and disjointed with researchers from various disciplines studying the phenomenon. Indeed, research findings have been published in a variety of outlets, thus impeding progress towards integrated frameworks that would more closely resemble real-world decision-making.

Third, health is just one of the areas in which intertemporal choices are studied. While some of the factors influencing intertemporal choices in health may be like those in other domains such as finances, there are circumstances that pertain to health decisions that are unique. For instance, the role of genetics makes it such that an individual will never have complete control over their health outcomes regardless of their choices. Therefore, it is not surprising that researchers have discovered different discounting patterns when it comes to making intertemporal tradeoffs with health outcomes (Chapman, 
1996). Considering this, researchers examining intertemporal health choices are likely to encounter unique obstacles when it comes to simulating and developing approaches to positively influence real-world health decision-making. This highlights the importance of identifying and understanding the ways in which individuals balance their intertemporal health choices, including how they relate to other choices they make in their lives such as tradeoffs between health and other responsibilities like work or childcare.

Alas, intertemporal choice studies in health invariably fail to acknowledge and integrate the impact of environmental factors and the social determinants of health into explanations for short-sighted decision-making. There seems to have been a myopic focus on examining behaviors consistent with maximizing short-term pleasures and minimizing present discomforts (e.g., Urminsky \& Zauberman, 2016). As such, an overwhelmingly overlooked fact is that not all short-sighted health decisions achieve these goals. In many instances, individuals consciously sacrifice their health as a result of other responsibilities. Consider for example an individual that does not get enough sleep. Aside from the condition of insomnia, the reasons for sleep deprivation could relate to pleasure (e.g., staying up late to watch one's favorite TV show), but they may also relate to family responsibilities, working overtime or meeting an important deadline. These last three examples are not only more compatible with the social determinants of health (since income, education level and other factors may influence work and family responsibilities), but also serve as an illustration of the reality of real-world decision-making, where individuals may consciously decide to make intertemporal tradeoffs, whilst cognizant of the potential consequences and aside from the psychological explanations described above.

This suggests that individuals are engaged in some sort of implicit process for managing and rationalizing their intertemporal decisions, at least some of the time, such as when making health sacrifices. Exposing that explicit process has important implications for advancing our understanding of the complexities of intertemporal health choices as well as integrating what is known about the various psychological, environmental, and social factors that influence decisionmaking. This paper contributes to that goal by introducing a new conceptual model, which demonstrates how intertemporal choices are traded over time based on the conceptualization of health as a renewable resource.

\section{Conceptualizing health as a renewable resource}

It is apparent that both experts and lay people view health as, in part, renewable and fungible (Williamson \& Carr, 2009). This notion unites the various psychological explanations for short-sighted decision-making based on maximizing shortterm utility with the fact that many individuals also make health sacrifices to achieve other goals. Indeed, through their choices, individuals can either diminish their health reserves (e.g., sleep deprivation, overconsuming unhealthy foods and substances such as drugs, alcohol, cigarettes) or replenish them (e.g., getting an adequate amount of sleep, practicing meditation, exercising, healthy eating, and taking vitamins or medications as prescribed). Moreover, even without conscious actions, the human body is constantly in a state of turning over new cells and has the ability to recover from illness as well as reverse even substantial tissue damage. For instance, Morgan (2017) explains that when an individual stops drinking alcohol, liver cells regenerate, and fatty liver disease can be partially or even completely reversed. Similarly, the detrimental effects of smoking can be remedied with smoking cessation (Beers \& Morrisey, 2011); and depending on how long an individual has been smoking or drinking, the tissues can return to pre-damaged states, appearing as if no damage had even occurred (Königshoff et al., 2013; Mortaz et al., 2011). While the ability to repair damaged tissues and recover from illness declines throughout the lifespan, the body is still capable of healing and repair until death. Therefore, under the optimal circumstances, and often with the help of modern medicine, individuals can restore lost or sacrificed health reserves and manage their health as a renewable resource through their intertemporal choices.

\section{Health as a Renewable Resource model}

Figure 2 presents a new conceptual model that facilitates intertemporal health decision-making that is based on the renewable properties of health. In the figure, an individual's health resource is represented by a reservoir that is filled and drained through a complex input-output mechanism.

The model comprises the following components. First, the reservoir itself in which health or vitality is stored; the absolute size of the reservoir is different for different people and is largely genetically determined. Second, input and output taps which in turn fill (add health resources) and drain (subtract health resources) the reservoir. Finally, two interconnected mechanisms which control the input and output taps, and thus the rate at which the reservoir is both filled and emptied. These mechanisms comprise, on the one hand, conscious or volitional behaviors (endogenous processes), and on the other hand, unconscious or non-volitional processes (exogenous processes). Conscious or volitional behaviors include such things as diet, exercise, hygiene (mental and physical), social life, and rest. Generally, conscious behaviors such as exercising regularly, engaging in meditation and mindfulness, eating nutritious food, getting adequate sleep, and taking preventative measures to avoid injury or 


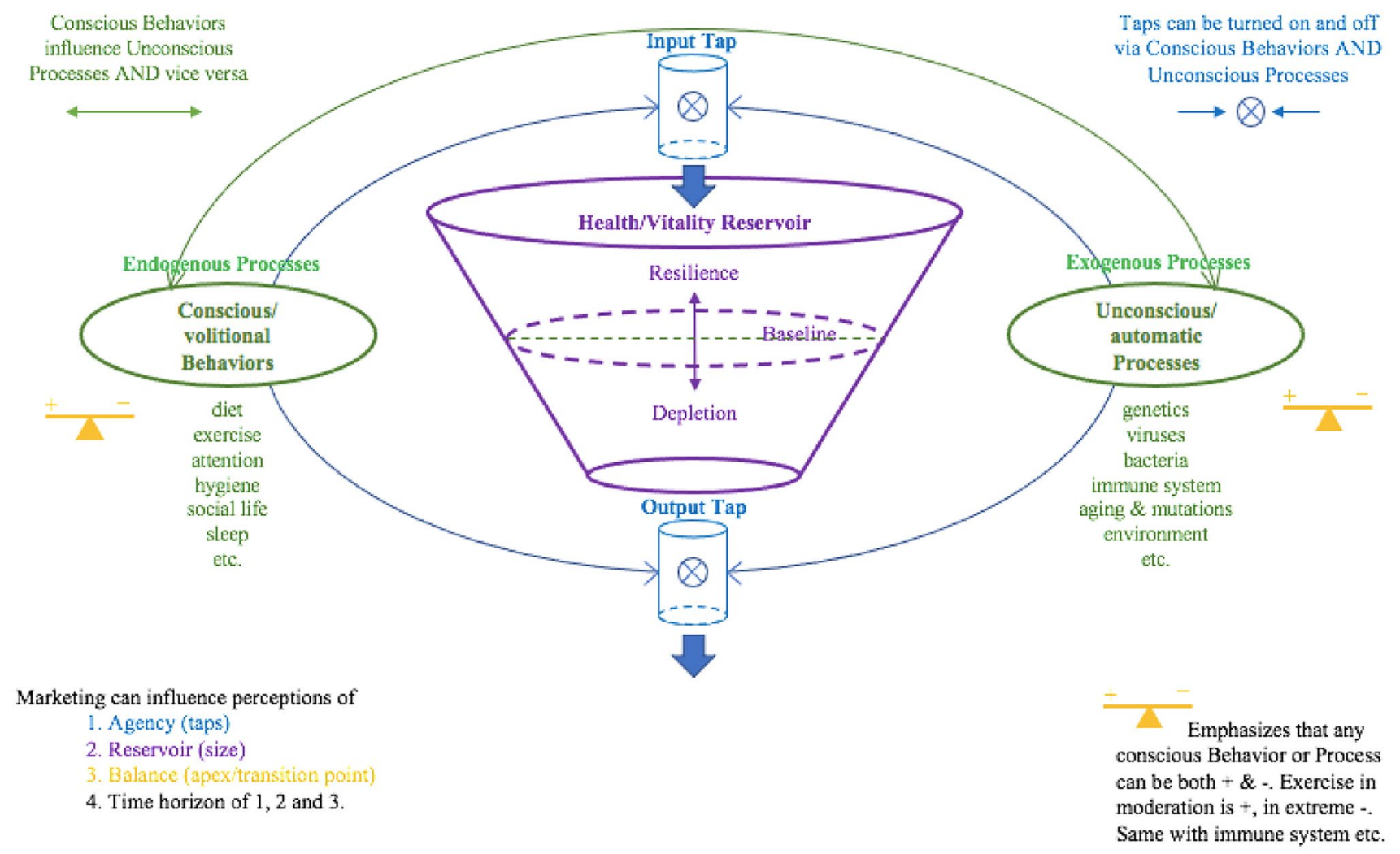

Fig. 2 Health as a Renewable Resource model

disease (e.g., quitting smoking, avoiding risky activities such as unprotected sex, practicing thorough hand hygiene) fill one's health reservoir while the opposite drain the reservoir. Unconscious or non-volitional processes include such things as genetics, immune system functioning, aging, viruses, bacteria, and the wider environment in which the individual lives. As is show in the model, these two processes influence one another bidirectionally: conscious behaviors can influence unconscious processes and vice versa. So, for example, exercise can boost the immune system, and genetics can influence psychological traits such as contentiousness. Similarly, one's physical and social environment can constrain conscious choices, and one can, within reason, change one's environment.

The reservoir has a reference point which corresponds to an individual's baseline health status and to perceptions of feeling "well" or "healthy." If health resources fall below this baseline the individual enters a depleted state in which they initially feel unwell, and from which point their health may decline to a juncture at which they are unable to function in daily life. If resources are added such that the reservoir fills above the baseline, the individual builds health resilience. This represents an opportunity for individuals to accumulate health slack or reserves to be used later that provide some resiliency in the system. In other words, an individual may be particularly diligent about their health behaviors if they know that a future event may be particularly demanding on their system. For example, soon-to-be parents may focus on healthy behaviors before their baby's delivery date because they realize that they won't be able to focus as much on their own health when they have a newborn to care for. While health resource slack can be manipulated, there are limits to how much resiliency can be stored in the reservoir. This, like the overall size of the reservoir, is determined in part by genetic factors.

The balance symbol in the model stresses the notion of balance or, technically, hormesis. Hormesis is the characteristic of many biological and psychological processes, which have biphasic or triphasic responses to increasing amount of a particular substance or activity (Calabrese, 2008; Radak et al., 2008). So, for example, moderate amounts of exercise can be very beneficial, whilst over exercising can result in damage. Similarly, with unconscious processes such as the immune system: an overactive immune system can result in auto-immune problems and an underactive immune system leaves the body vulnerable.

It is important to note that the Health as a Renewable Resource (HRR) model is not meant to precisely explain 
how or why people get sick, but to help explain why and how individuals make health decisions over time that may increase or decrease the risk of ill health effects. For example, after successfully training and completing a $5 \mathrm{k}$ run, an individual may feel they have earned a period of inactivity and overindulgence. Conversely, after an intemperate holiday, a person may decide to change their diet. As these examples illustrate, the HRR model demonstrates that individuals can make conscious choices in managing their health reserves over time. As a result, the model has important implications for our understanding of why and how individuals make health decisions in at least two ways. First, being able to manage one's health reserve greatly increases the perceived control an individual has over their health (Infurna \& Gerstorf, 2014; Jerant et al., 2008; Wallston et al., 2007). Second, if an individual believes that health has renewable qualities (and that they can control the inputs), then they may engage in unhealthy behaviors since they can always "make up for it later." And conversely, they may engage in healthy behaviors to make up for past lapses.

\section{The model applied to COVID}

The model has both general application (i.e., health over the lifetime of a person) and specific application (i.e., health or well-being as it relates to a specific disease or condition). So far, we have considered the general application of the model. Let us now turn to a discussion of how the elements in the model impact the risk of developing a specific disease: COVID 19.

At the time of writing this paper, COVID is the leading cause of death in many countries around the world (Koh et al., 2021). What can the model teach us about managing our heath during a pandemic? First, the model clearly differentiates endogenous (within conscious control) and exogenous factors (outside of direct conscious control), and that each can have positive (fill) and negative (drain) effects on a person's health reservoir. The model also shows that both endogenous and exogenous factors influence one another.

For COVID-19, the factors that are within direct conscious control and that close the output tap of the reservoir, go beyond the well-advertised wearing of masks and maintaining social distancing, to include taking active steps to reduce viral density over time: such as opening windows to increase ventilation, maximizing time outside, minimizing time spent in close proximity to others, and avoiding strenuous activity (that increase oxygen consumption) in the presence of others (e.g., Jin et al., 2021; Liu et al., 2020; Yadaw et al., 2020; Wang et al., 2020).

However, perhaps the greatest impact on closing the output tap of the reservoir is the choice to get vaccinated. Both the new mRNA and more traditional vaccines have shown excellent results in their ability to elicit the production of antibodies to the virus, with vaccinated people being less likely to become infected, and if they do, less likely to transmit the virus (e.g., Harder et al., 2021). Understandably, the longevity of protection afforded by these vaccines is still under study, as are their long-term side effects. While a complete picture will not emerge for some time, there is no doubt that the decision to get vaccinated reflects an endogenous factor, a conscious decision, that has direct implications for one's health.

Factors that are exogenous (at the time of the pandemic) and out of an individual's control, which drain the health reservoir (open the output tap) and thus increase the risk of severe or terminal COVID infection include age, sex at birth (men are at a higher risk than women), having cardiovascular disease, respiratory disease, diabetes, and being obese ${ }^{3}$ (e.g., Jin et al., 2021; Yadaw et al., 2020). Factors that are within conscious control and that positively impact exogenous factors are things such as boosting the body's vitamin D levels, either through taking vitamin D supplements and/ or spending time outside in the sun. Vitamin D improves the functioning of the immune system (Aranow, 2011), thereby filling the health reservoir and improving resilience to COVID $^{4}$ (e.g., Brenner \& Schöttker, 2020; Charoenngam et al., 2021; Griffin et al., 2020; Teshome et al., 2021; Trovas \& Tournis, 2021). Exogenous factors also effect endogenous conscious choices. For example, social pressure from one's school peer group or family may change perceptions of risk, with adolescents being particularly susceptible to engaging in risky behavior with respect to COVID (e.g., Ding et al., 2020; Nivette et al., 2021). Using the model, health marketers can help individuals understand the various factors that fill or drain their reservoir in order to improve resilience to COVID-19 and other conditions. Specific marketing implications of the model are described in detail below.

\section{Marketing implications}

The HRR model has three important implications for marketing communications and public health interventions. First, marketing can influence perceptions of individuals' reservoir size. While everyone is born with a fixed reservoir (largely based on genetic material), individuals may perceive that their reservoir is a different size at different points in their lives. Like body dysmorphia (e.g., Lemma, 2009), some individuals may have distorted perceptions of their

\footnotetext{
${ }^{3}$ Obviously, some of these factors, such as respiratory disease due to smoking, may be the long-term result of conscious choices by an individual.

${ }^{4}$ At the time of writing, the research evidence points to vitamin D potentially being beneficial as both a prophylaxis and as a co-treatment of COVID-19. However, the research is still ongoing.
} 
health reservoir. Thus, people may be inclined to believe that they have a larger or smaller capacity for unhealthy behaviors or risk-taking based on their personal circumstances. For example, a young person may believe that they are invincible and that they have a near infinite reservoir, resulting in greater risk-taking behaviors. Such may be the case with younger individuals failing to adhere to COVID19 related restrictions and attending social gatherings (e.g., Graupensperger et al., 2021). Making individuals aware of the limitations of their reservoir can help them realize that risks do add up and have the potential to negatively impact their health.

Second, marketing can use the HRR model to highlight those factors that drain one's health reservoir and those factors that fill the reservoir (cf., Maibach et al., 2006). Similarly, marketing can influence perceptions of the time and effort needed to offset various unhealthy behaviors. In other words, if individuals are likely to engage in compensation strategies to make up for activities or situations that drain the reservoir (e.g., taking vitamin supplements during winter months or exercising during periods of high stress), then providing them with explicit quantifications of how much compensation is needed (e.g., types and number of vitamins, minutes and intensity of exercise) may be useful. Such an intervention could be part of public education and awareness campaigns or implemented through policy changes (e.g., requiring food manufacturers to include this type of information on their packaging) (cf., Andrews, 2011). Similar strategies could be used to leverage the innate regenerative properties of the human body. For example, highlighting the ability to heal and regenerate damaged tissue would be helpful in motivating smokers to quit cigarettes. Realizing that tissue damage is in part reversible (Kim et al., 2004) could be just what some individuals need to join and follow through on smoking cessation programs as well as drug or alcohol rehabilitation.

Finally, marketing can help individuals strike a balance between choices and situations that fill and drain the health reservoir (e.g., Grier \& Bryant, 2005). While it would be ideal for people to eliminate all unhealthy activities, this is unlikely to happen for both pragmatic and situational reasons. A more realistic approach would be to accept that many individuals will continue to engage in behaviors and expose themselves to situations that are detrimental to their health and then attempt to compensate with choices that restore vitality (Rabia et al., 2006). Scientific evidence shows that if individuals balance unhealthy with healthy behaviors, a high level of overall health can be maintained (e.g., Li et al., 2018). As such, acknowledging that health has renewable properties and that individuals can manage their health reserves is an important step in developing successful interventions to promote health and consumer well-being.
The HRR model demonstrates how the actions of individuals can be beneficial or play a toll on one's health. However, anything done to the extreme, even healthy behaviors, can backfire. For example, overexercising can cause tissue damage and increase susceptibility to injury. Similarly, if a person restricts their diet too much, they may miss out on essential nutrients. In this way, a balance is important to maintain. As such, the model can be used as a starting point to help individuals visualize the effect of their behaviors on their health and for marketing communications to highlight the importance of balance in health impacting decisions. This implication opens up new business opportunities that could help individuals manage (and balance) their health reservoir. For example, the collection and monitoring of biometric data through widely used digital applications (e.g., Fitbit, Apple watch) provides the prospect of helping individuals quantify the effectiveness of their health compensation strategies based on individualized data (cf., Massoomi \& Handberg, 2019). Programs could be developed to help people track their health choices and develop detailed plans to ensure that individuals realize the benefits of their positive intentions (i.e., helping individuals follow through on plans to engage in future healthy behaviors). Applications that allow individuals to track their health choices, categorize them into investing or divesting health behaviors, and quantify them based on scientific evidence would also help people to better visualize their available health reserves. Principles of gamification (e.g., Plangger et al., 2019; Robson et al., 2015) could then be used to help motivate individuals based on the state of their health reservoir and take actions to balance their health behaviors.

\section{Future research}

The HRR model affords new research opportunities for health marketing (Table 2). These include not only examining and evaluating the impact of the various marketing implications discussed above, but also exploring and advancing the conceptualization of health presented in this paper. If the goal of health marketing is to help individuals make healthy choices, then research based on the renewable properties of health can contribute to our understanding of how these choices are made, how health as a resource is balanced, and how various activities contribute to managing one's health reservoir. Given that some people will attempt to compensate for unhealthy behaviors (in one way or another), a valuable endeavor would be to seek to understand what these exchange processes look like. With the health reservoir to facilitate these exchanges, research can explore individuals' perceptions of the boundaries of their health decision-making as well as the timeline or window for compensatory efforts. This 
Table 2 Example of research opportunities afforded by the HRR model

\begin{tabular}{|c|c|}
\hline Research Category & Example Research Questions \\
\hline $\begin{array}{l}\text { Exploring the Conceptualization of Health as a Renewable } \\
\text { Resource }\end{array}$ & $\begin{array}{l}\text { How does one manage their health reserves in the complexity of real } \\
\text { life? } \\
\text { Which activities, and in what amounts, are thought to contribute to fill- } \\
\text { ing or draining one's health reservoir? } \\
\text { What factors impact an individuals' perception of their reservoir size? } \\
\text { What factors impact an individuals' perception of their available health } \\
\text { reserves? } \\
\text { What boundaries do individuals place on the exchange processes that } \\
\text { can be made through the model? } \\
\text { What is the perceived time horizon that individuals place on engaging } \\
\text { in health balancing activities? } \\
\text { What cues do individuals use to identify if they are in a replenished or } \\
\text { depleted state? } \\
\text { How do individuals weigh the risks of engaging in unsafe or risky } \\
\text { behaviors in relation to the resource levels in their reservoir? } \\
\text { To what extent do individuals perceive health as a renewable resource } \\
\text { and how does that impact health balancing behaviors? } \\
\text { Which metaphors help individuals to best visualize and manage their } \\
\text { health? }\end{array}$ \\
\hline $\begin{array}{l}\text { Implementation and Evaluation of Marketing Interventions Based } \\
\text { on the Model }\end{array}$ & $\begin{array}{l}\text { How to craft marketing communications to elicit the health reservoir } \\
\text { model in consumers' minds? } \\
\text { What factors (exogenous and endogenous) influence the adoption and } \\
\text { use of the model? } \\
\text { To what degree (and under what circumstances) does the use of the } \\
\text { implicit use of the reservoir model change consumer's health decision } \\
\text { making? } \\
\text { To what degree (and under what circumstances) does the use of the } \\
\text { explicitly directed use of the reservoir model change consumer's } \\
\text { health decision making? } \\
\text { What types of health decisions is the reservoir metaphor most suited to } \\
\text { change consumer behavior? }\end{array}$ \\
\hline
\end{tabular}

research has implications for developing tools to help individuals foster introspection about the limits and capacity of their health, including understanding when they are in a depleted state or when they have an opportunity to build resilience.

Using the model as a guide, health marketing researchers could also uncover new ways to highlight the role of behaviors that may not immediately or intuitively appear to be related to health. For example, revealing the link between mental health and attention (e.g., Keller et al., 2019), or the role that cold water immersion could play in alleviating mild depression (e.g., Shevchuk, 2008). Moreover, an intriguing research question becomes: how do individuals weigh the risks of engaging in unsafe behaviors or following health guidelines in relation to the resource levels in their reservoir? And more broadly, how does one manage their health reserves in the complexity of real life? This framing would help to demystify the impact of not only biological, but also psychological, social, and economic influences on health decision-making that could be targeted by health marketing communications as ways to turn on or off the taps of the health reservoir.

Similarly, using the model as a guiding tool, researchers could explore individuals' perceptions of the types of behaviors and which combinations allow an individual to fill and drain their health reservoir. As evident in studies on lay views - the implicit theories that individuals construct about the causes and consequences of many phenomena (Furnham, 1988; Wyer, 2003), there is often a disconnect between individuals' thoughts and beliefs and what medical studies reveal about illness, injury, and the human body (Karnani et al., 2014). This can be reflected as a tension between a person's lived experience and generalized science on the topic (e.g., I went to a party and did not get COVID, therefore I must be immune, or the press/government are exaggerating the risks), a misunderstanding of the facts, or a failure to acknowledge current scientific evidence (cf. Hsiao, 2021). As one example, McFerran and Mukhopadhyay (2013) demonstrate that many people believe that lack of exercise is a primary factor in obesity, despite scientific evidence pointing to diet as the 
most important factor for weight management. In this way, the various belief systems that individuals hold about their bodies and health in general, may have a strong influence on how they actually manage their health reservoir.

A significant research endeavor would then involve exploring the degree to which individuals view health as a renewable resource and how this conceptualization or belief system influences individuals' perceptions of health-impacting behaviors. Similar to experiments on implicit theories in health such as the entity (health is fixed) vs. incremental (health is malleable) lay views (Bunda \& Busseri, 2019), the health as a renewable resource could be measured and even manipulated (as a lay view) to explore its influence on health-impacting behaviors over time. Some individuals may already view health as something that can be renewed through conscious and unconscious efforts. But for others, it may be less intuitive. Therefore, if individuals are shown that health has renewable properties and given a simple way to visualize the impact of endogenous and exogenous variables, it may empower them to more actively manage their health resources. The results of studies exploring this intervention would add to the growing literature on lay views and health and also, complement findings showing that when individuals believe in the plasticity or adaptability of their bodies (and potentially the renewable properties of their health), they are more likely to overcome health challenges and achieve their wellness goals (e.g., Burnette, 2010).

It is clear that lay views are a vital part of how people make sense of the world and metaphors allow lay views to come to life and help individuals simplify and visualize complex systems (Landau et al., 2018). The HRR model is built on the belief that health has renewable properties and uses the health reservoir as a metaphor for health decisionmaking. While this metaphor may be willingly adopted by many, it is also possible that the health reservoir does not resonate with everyone. As such, future research should seek to explore the metaphors that individuals use to make sense of their health decisions over time. Other ways of visualizing and managing intertemporal changes over time may be more appropriate for some people. A health bank account, for instance, could be another useful metaphor for the layperson that is still consistent with the health as a renewable resource conceptualization. Instead of the notion of filling and draining a reservoir, this alternative metaphor might involve language around investing and divesting in one's health as well as "balancing health accounts." It is likely that certain individuals will make sense of their health-impacting activities in different ways and with different metaphors, thus providing the opportunity for segmenting public health initiatives based on the notion of health as a renewable resource (Fetterman et al., 2016). Indeed, regardless of the metaphor used, the HRR conceptualization has the potential to better align individuals' belief systems about their health with scientific evidence and to empower individuals to understand and manage their health-impacting decisions.

\section{Conclusion}

While health is a complex construct, research to date has provided many insights into how individuals make healthimpacting decisions. A major challenge that health marketers face in bringing this research into practice is a lack of integration amongst the various macro and micro level factors that influence decision-making (some within an individual's control and others not). The purpose of this paper was to contribute to a more integrated understanding of health decision-making by reviewing and evaluating a multidisciplinary body of knowledge. In doing so, a new conceptual model was developed, the Health as a Renewable Resource (HRR) model, that demonstrates how individuals manage their health on a daily basis through the renewable or semi-fungible qualities of health. The model provides health marketers with a useable tool that is easy to understand for the layperson and scholars with new research opportunities based on a novel conceptualization of health.

\section{References}

Adams, J., \& Nettle, D. (2009). Time perspective, personality and smoking, body mass, and physical activity: An empirical study. British Journal of Health Psychology, 14(1), 83-105.

Andrews, J. C. (2011). Warnings and Disclosures. In B. Fischhoff, N. T. Brewer, \& J. S. Downs (eds.), Communicating risks and benefits: An evidenced-based users guide Silver (pp. 149-61). Spring, MD: U.S. Food and Drug Administration.

Aranow, C. (2011). Vitamin D and the immune system. Journal of Investigative Medicine, 59(6), 881-886.

Bartels, D. M., \& Rips, L. J. (2010). Psychological connectedness and intertemporal choice. Journal of Experimental Psychology: General, 139(1), 49.

Bartels, D. M., \& Urminsky, O. (2011). On intertemporal selfishness: How the perceived instability of identity underlies impatient consumption. Journal of Consumer Research, 38(1), 182-198.

Beers, M. F., \& Morrisey, E. E. (2011). The three R's of lung health and disease: Repair, remodeling, and regeneration. The Journal of Clinical Investigation, 121(6), 2065-2073.

Bernhardt, J. M. (2006). Improving health through health marketing. Preventing Chronic Disease, 3(3).

Berns, G. S., Laibson, D., \& Loewenstein, G. (2007). Intertemporal choice-toward an integrative framework. Trends in Cognitive Sciences, 11(11), 482-488.

Bonaccorsi, G., Pierri, F., Cinelli, M., Flori, A., Galeazzi, A., Porcelli, F., \& Pammolli, F. (2020). Economic and social consequences of human mobility restrictions under COVID-19. Proceedings of the National Academy of Sciences, 117(27), 15530-15535.

Brenner, H., \& Schöttker, B. (2020). Vitamin D insufficiency may account for almost nine of ten COVID-19 deaths: Time to act. 
comment on: "Vitamin D deficiency and outcome of COVID-19 patients". nutrients 2020, 12, 2757. Nutrients, 12(12), 3642.

Bunda, K., \& Busseri, M. A. (2019). Lay theories of health, self-rated health, and health behavior intentions. Journal of Health Psychology, 24(7), 979-988.

Burnette, J. L. (2010). Implicit theories of body weight: Entity beliefs can weigh you down. Personality and Social Psychology Bulletin, $36(3), 410-422$.

Calabrese, E. J. (2008). Hormesis and medicine. British Journal of Clinical Pharmacology, 66(5), 594-617.

Chapman, G. B. (1996). Temporal discounting and utility for health and money. Journal of Experimental Psychology: Learning, Memory, and Cognition, 22(3), 771.

Charoenngam, N., Shirvani, A., \& Holick, M. F. (2021). Vitamin D and its potential benefit for the COVID-19 pandemic. Endocrine Practice.

Crié, D., \& Chebat, J. C. (2013). Health marketing: Toward an integrative perspective. Journal of Business Research, 66(1), 123-126.

Ding, Y., Du, X., Li, Q., Zhang, M., Zhang, Q., Tan, X., \& Liu, Q. (2020). Risk perception of coronavirus disease 2019 (COVID-19) and its related factors among college students in China during quarantine. PLoS One, 15(8), e0237626.

Fetterman, A. K., Bair, J. L., Werth, M., Landkammer, F., \& Robinson, M. D. (2016). The scope and consequences of metaphoric thinking: Using individual differences in metaphor usage to understand how metaphor functions. Journal of Personality and Social Psychology, 110(3), 458-476.

Frederick, S., Loewenstein, G., \& O'donoghue, T. (2002). Time discounting and time preference: A critical review. Journal of Economic Literature, 40(2), 351-401.

Fujita, K., Trope, Y., Liberman, N., \& Levin-Sagi, M. (2006). Construal levels and self control. Journal of Personality and Social Psychology, 90, 351-367.

Furnham, A. (1988). Lay theories: Everyday understanding of problems in the social sciences. Pergamon Press.

Gandini, S., Botteri, E., Iodice, S., Boniol, M., Lowenfels, A. B., Maisonneuve, P., \& Boyle, P. (2008). Tobacco smoking and cancer: A meta-analysis. International Journal of Cancer, 122(1), 155-164.

Graupensperger, S., Lee, C. M., \& Larimer, M. E. (2021). Young adults underestimate how well peers adhere to COVID-19 preventive behavioral guidelines. The Journal of Primary Prevention, 1-10.

Grier, S., \& Bryant, C. A. (2005). Social marketing in public health. Annual Review Public Health, 26, 319-339.

Griffin, G., Hewison, M., Hopkin, J., Kenny, R., Quinton, R., Rhodes, J., \& Thickett, D. (2020). Vitamin D and COVID-19: evidence and recommendations for supplementation. Royal Society Open Science, 7(12), 201912.

Harder, T., Koch, J., Vygen-Bonnet, S., Külper-Schiek, W., Pilic, A., Reda, S., \& Wichmann, O. (2021). Efficacy and effectiveness of COVID-19 vaccines against SARS-CoV-2 infection: Interim results of a living systematic review, 1 January to 14 May 2021. Eurosurveillance, 26(28), 2100563.

Hardisty, D. J., \& Weber, E. U. (2009). Discounting future green: Money versus the environment. Journal of Experimental Psychology: General, 138(3), 329.

Hershfield, H., \& Bartels, D. (2018). The Future Self. In G. Oettingen, A. T. Sevincer, \& P. M. Gollwitzer (Eds.), The Psychology of Thinking about the Future (pp. 89-109). The Guilford Press.

Hsiao, T. (2021). Lived Experiences Aren't Special. Quillette, May 24.

Infurna, F. J., \& Gerstorf, D. (2014). Perceived control relates to better functional health and lower cardio-metabolic risk: The mediating role of physical activity. Health Psychology, 33(1), 85.

Jerant, A., Moore, M., Lorig, K., \& Franks, P. (2008). Perceived control moderated the self-efficacy-enhancing effects of a chronic illness self-management intervention. Chronic Illness, 4(3), 173-182.
Jin, J., Agarwala, N., Kundu, P., Harvey, B., Zhang, Y., Wallace, E., \& Chatterjee, N. (2021). Individual and community-level risk for COVID-19 mortality in the United States. Nature Medicine, 27(2), 264-269.

Joireman, J., Shaffer, M. J., Balliet, D., \& Strathman, A. (2012). Promotion orientation explains why future-oriented people exercise and eat healthy evidence from the two-factor consideration of future consequences-14 scale. Personality and Social Psychology Bulletin, 38(10), 1272-1287.

Karnani, A., McFerran, B., \& Mukhopadhyay, A. (2014). Leanwashing: A hidden factor in the obesity crisis. California Management Review, 56(4), 5-30.

Keller, A. S., Leikauf, J. E., Holt-Gosselin, B., Staveland, B. R., \& Williams, L. M. (2019). Paying attention to attention in depression. Translational Psychiatry, 9(1), 1-12.

Khullar, D., \& Chokshi, D. A. (2018). Health, income, \& poverty: Where we are \& what could help. Health Affairs Health Policy Brief, 4.

Kim, B. K., \& Zauberman, G. (2009). Perception of anticipatory time in temporal discounting. Journal of Neuroscience, Psychology, and Economics, 2(2), 91.

Kim, H., Liu, X., Kobayashi, T., Conner, H., Kohyama, T., Wen, F. Q., \& Rennard, S. I. (2004). Reversible cigarette smoke extractinduced DNA damage in human lung fibroblasts. American Journal of Respiratory Cell and Molecular Biology, 31(5), 483-490.

Koh, H. K., Geller, A. C., \& VanderWeele, T. J. (2021). Deaths from COVID-19. Journal of the American Medical Association, 325(2), 133-134.

Komlos, J., Smith, P. K., \& Bogin, B. (2003). Obesity and the Rate of Time Preference: Is there a Connection, Munich Discussion Paper No. 2003-16.

Königshoff, M., Saglani, S., Marsland, B. J., \& Eickelberg, O. (2013). Rebuilding a diseased lung: Repair and regeneration. European Respiratory Journal, 41, 497-499.

Landau, M. J., Arndt, J., \& Cameron, L. D. (2018). Do metaphors in health messages work? Exploring emotional and cognitive factors. Journal of Experimental Social Psychology, 74, 135-149.

Lemma, A. (2009). Being seen or being watched? A psychoanalytic perspective on body dysmorphia. The International Journal of Psychoanalysis, 90(4), 753-771.

Lerner, J. S., Li, Y., \& Weber, E. U. (2013). The financial costs of sadness. Psychological Science, 24(1), 72-79.

Li, Y., Pan, A., Wang, D. D., Liu, X., Dhana, K., Franco, O. H., \& Hu, F. B. (2018). Impact of healthy lifestyle factors on life expectancies in the US population. Circulation, 138(4), 345-355.

Liberman, N., \& Trope, Y. (1998). The role of feasibility and desirability considerations in near and distant future decisions: A test of temporal construal theory. Journal of Personality and Social Psychology, 75(1), 5.

Liu, Y., Yan, L. M., Wan, L., Xiang, T. X., Le, A., Liu, J. M., \& Zhang, W. (2020). Viral dynamics in mild and severe cases of COVID-19. The Lancet Infectious Diseases, 20(6), 656-657.

Loewenstein, G. (1996). Out of control: Visceral influences on behavior. Organizational Behavior and Human Decision Processes, 65(3), 272-292.

Loewenstein, G., \& Prelec, D. (1992). Anomalies in intertemporal choice: Evidence and an interpretation. The Quarterly Journal of Economics, 107(2), 573-597.

MacKillop, J., Amlung, M. T., Few, L. R., Ray, L. A., Sweet, L. H., \& Munafò, M. R. (2011). Delayed reward discounting and addictive behavior: A meta-analysis. Psychopharmacology (berl), 216, 305-321.

Magen, E., Dweck, C., \& Gross, J. (2008). The Hidden-Zero Effect. Psychological Science, 19(7), 648-649.

Maibach, E. W., Van Duyn, M. A. S., \& Bloodgood, B. (2006). Peer reviewed: a marketing perspective on disseminating 
evidence-based approaches to disease prevention and health promotion. Preventing Chronic Disease, 3(3).

Malkoc, S. A., \& Zauberman, G. (2019). Psychological analysis of consumer intertemporal decisions. Consumer Psychology Review, 2(1), 97-113.

Malkoc, S. A., Zauberman, G., \& Bettman, J. R. (2010). Unstuck from the concrete: Carryover effects of abstract mindsets in intertemporal preferences. Organizational Behavior and Human Decision Processes, 113(2), 112-126.

Marmot, M., \& Wilkinson, R. G. (2006). Social determinants of health. Second edition. Oxford University Press.

Marmot, M., Friel, S., Bell, R., Houweling, T. A., Taylor, S., \& Commission on Social Determinants of Health. (2008). Closing the gap in a generation: health equity through action on the social determinants of health. The Lancet, 372(9650), 1661-1669.

Massoomi, M. R., \& Handberg, E. M. (2019). Increasing and evolving role of smart devices in modern medicine. European Cardiology Review, 14(3), 181.

McFerran, B., \& Mukhopadhyay, A. (2013). Lay theories of obesity predict actual body mass. Psychological Science, 24(8), $1428-1436$.

Morgan, T. (2017). Treatment of Alcoholic Liver Disease. Gastroenterology \& Hepatology, 13(7), 425-427.

Mortaz, E., Masjedi, M. R., \& Rahman, I. (2011). Outcome of smoking cessation on airway remodeling and pulmonary inflammation in COPD patients. Tanaffos, $10(3), 7$.

Nivette, A., Ribeaud, D., Murray, A., Steinhoff, A., Bechtiger, L., Hepp, U., \& Eisner, M. (2021). Non-compliance with COVID19-related public health measures among young adults in Switzerland: Insights from a longitudinal cohort study. Social Science \& Medicine, 268, 113370.

Pham, M. (2013). The seven sins of consumer psychology. Journal of Consumer Psychology, 4(23), 411-423.

Picone, G., Sloan, F., \& Taylor, D., Jr. (2004). Effects of Risk and Time Preference and Expected Longevity on Demand for Medical Tests. Journal of Risk and Uncertainty, 28(1), 39-53.

Plangger, K., Campbell, C., Robson, K., \& Montecchi, M. (2019). Little rewards, big changes: Using exercise analytics to motivate sustainable changes in physical activity. Information \& Management, 103216.

Rabia, M., Knäuper, B., \& Miquelon, P. (2006). The eternal quest for optimal balance between maximizing pleasure and minimizing harm: The compensatory health beliefs model. British Journal of Health Psychology, 11(1), 139-153.

Radak, Z., Chung, H. Y., Koltai, E., Taylor, A. W., \& Goto, S. (2008). Exercise, oxidative stress and hormesis. Ageing Research Reviews, $7(1), 34-42$.

Raghunathan, R., Naylor, R. W., \& Hoyer, W. D. (2006). The unhealthy $=$ tasty intuition and its effects on taste inferences, enjoyment, and choice of food products. Journal of Marketing., $70(4), 170-184$.

Read, D. (2004). Intertemporal choice. Blackwell handbook of judgment and decision making, 424-443.

Redden, J. P. (2007). Hyperbolic discounting. In R. F. Baumeister \& K. D. Vohs (Eds.), Encyclopedia of Social Psychology. Thousand Oaks, CA: Sage.

Robson, K., Plangger, K., Kietzmann, J. H., McCarthy, I., \& Pitt, L. (2015). Is it all a game? Understanding the principles of gamification. Business Horizons, 58(4), 411-420.

Rothspan, S., \& Read, S. J. (1996). Present versus future time perspective and HIV risk among heterosexual college students. Health Psychology, 15(2), 131.

Rutchick, A. M., Slepian, M. L., Reyes, M. O., Pleskus, L. N., \& Hershfield, H. E. (2018). Future self-continuity is associated with improved health and increases exercise behavior. Journal of Experimental Psychology: Applied, 24(1), 72.
Schmidt, H. (2016). Chronic disease prevention and health promotion. In Public Health Ethics: Cases Spanning the Globe (pp. 137-176). Springer, Cham.

Shevchuk, N. A. (2008). Adapted cold shower as a potential treatment for depression. Medical Hypotheses, 70(5), 995-1001.

Shiv, B., \& Fedorikhin, A. (1999). Heart and mind in conflict: The interplay of affect and cognition in consumer decision making. Journal of Consumer Research, 26(3), 278-292.

Stremersch, S. (2008). Health and marketing: The emergence of a new field of research. International Journal of Research in Marketing, 25(4), 229-233.

Teshome, A., Adane, A., Girma, B., \& Mekonnen, Z. A. (2021). The impact of vitamin D level on COVID-19 infection: Systematic review and meta-analysis. Frontiers in Public Health, 9, 169.

Thaler, R. (1981). Some empirical evidence on dynamic inconsistency. Economics Letters, 1;8(3):201-207.

Thaler, R. H., \& Sunstein, C. R. (2009). Nudge: Improving decisions about health, wealth, and happiness. Penguin.

Trovas, G., \& Tournis, S. (2021). Vitamin d and covid-19. Hormones, 20(1), 207-208.

Urminsky, O. (2017). The role of psychological connectedness to the future self in decisions over time. Current Directions in Psychological Science, 26(1), 34-39.

Urminsky, O., \& Zauberman, G. (2016). The psychology of intertemporal preferences. The Wiley Blackwell handbook of judgment and decision making, 141-181.

Urminsky, O., \& Zauberman, G. (2017). The health consequences of intertemporal preferences. Routledge International Handbook of Self-Control in Health and Well-Being.

Wallston, K. A., et al. (2007). Perceived control. In S. Ayers (Ed.), Cambridge handbook of psychology, health and medicine (pp. 148-151). Cambridge University Press.

Wang, Y., Zhang, L., Sang, L., Ye, F., Ruan, S., Zhong, B., Song, T., et al. (2020). Kinetics of viral load and antibody response in relation to COVID-19 severity. Journal of Clinical Investigation, 130(10).

Willett, W. C., Koplan, J. P., Nugent, R., Dusenbury, C., Puska, P., \& Gaziano, T. A. (2006). Prevention of chronic disease by means of diet and lifestyle changes. In Disease Control Priorities in Developing Countries. 2nd edition. The International Bank for Reconstruction and Development/The World Bank.

Williamson, D. L., \& Carr, J. (2009). Health as a resource for everyday life: Advancing the conceptualization. Critical Public Health, 19(1), 107-122.

World Health Organization (2018). Noncommunicable diseases country profiles 2018. Retrieved January 2, 2020 from https://www. who.int/nmh/publications/ncd-profiles-2018/en/

Wyer, R. S. (2003). Social comprehension and judgment: The role of situation models, narratives, and implicit theories. Psychology Press.

Yadaw, A. S., Li, Y. C., Bose, S., Iyengar, R., Bunyavanich, S., \& Pandey, G. (2020). Clinical features of COVID-19 mortality: Development and validation of a clinical prediction model. The Lancet Digital Health, 2(10), e516-e525.

Zauberman, G., \& Lynch, J. G. (2005). Resource slack and propensity to discount delayed investments of time versus money. Journal of Experimental Psychology: General, 134(1), 23-37.

Zauberman, G., Kim, B. K., Malkoc, S. A., \& Bettman, J. R. (2009). Discounting time and time discounting: Subjective time perception and intertemporal preferences. Journal of Marketing Research, 46(4), 543-556.

Zhao, M., Hoeffler, S., \& Zauberman, G. (2007). Mental simulation and preference consistency over time: The role of process-versus outcome-focused thoughts. Journal of Marketing Research, 44(3), 379-388.

Publisher's Note Springer Nature remains neutral with regard to jurisdictional claims in published maps and institutional affiliations. 